\title{
Eportfolio Implementation in a Multiple Campus Environment 4 - Disruptive Change and Innovation
}

\author{
Marie B. Fisher, Andrew J. Hill \\ Australian Catholic University, Australia
}

\begin{abstract}
Eportfolio is used as a concept and practice that facilitates diverse opportunities using technology to profile, reflect on, and progress career development as well as promote and engage learning [1] [2]. Reflective practice is encouraged in the milieu of academic learning, teaching, personal career development and in the professions as it closes the self-regulation 'loop' essential for metacognitive monitoring of learning. At our University, the Executive have been challenged when encouraging innovation, active personal learning and digital literacy whilst attempting to implement this technology into a multiple campus university environment; predominantly due to an environment filled by rapid disruptive change and uncertain government funding initiatives. The aim of this paper is to outline the changes that continue to hinder Eportfolio implementation in a multiple campus environment, share strategies we use to manage this process in our journey to promote adoption, and improve implementation through seeking and responding to feedback from the global community.
\end{abstract}

\section{Introduction}

The aim of this paper is to reflect upon and share our experiences of Eportfolio adoption and implementation working in a multiple campus university environment. In addition, we seek feedback from the global community on approaches and methods that could be explored to increase adoption. Through sharing our knowledge, we will outline the challenges that continue to hinder Eportfolio implementation in a multiple campus environment, communicate strategies used to manage this process, while continuing to promote use, uptake and accommodate feedback from the global community to help us explore and adapt to new ways of working through these changes.

\section{Literature Review}

At the Australian Catholic University, in a multiple campus environment, Eportfolio is promoted as a concept and practice that facilitates the process of engaging opportunities using technology to tell your story: develop your profile, reflect upon achievements, fulfil professional accreditation requirements and progress career development while at the same time displaying digital literacy and increasing engagement with lifelong learning to produce a product or 'Eportfolio' [1], [2], [3].

Digital portfolios or Eportfolios as they are more commonly referred to, evolved from paper portfolios used by educational institutions and employers to collect evidence of meeting assessment accreditation or certification in professions such as nursing and teaching, as well as reflective practice, continuous improvement and engagement in contemporary learning and teaching activities [2], [4], [5].

In the last two decades Eportfolios have become more complex due to technical advances from the 1990s as well as more accessible to a wider audience due to significant improvement in Web 2.0 technologies and the capacity of the internet to change strategies for learning and teaching [2]. At ACU the process of developing Eportfolios is complex due in part to discipline requirements, assessment and professional accreditation [2], [3], [4]. Research on Eportfolio implementation experiences conducted at Griffith University in Queensland Australia from 2008-2011 [4] also supports the authors' observations and experiences at ACU [2], [3] that adoption and implementation of Eportfolios was more likely to occur if support and strategic directions were clearly communicated from the institution outlining how this technology tool would be supported by eLearning and reflective practice approaches to collecting, storing and profiling evidence [3], [5].

Disruptive change and innovation occurring in the Higher Education environment are having a significant impact on 'digital literacy' of both staff and students engaged in learning and teaching as technological change outpaces society's ability to accommodate and adapt to changes at the same time [6]. Research conducted in early 2015 by the National Tertiary Education Union Survey (NTEU) of both union members and non-members has shown that while digital literacy and administration 
demands are increasing, institutions are struggling to maintain adequate levels of technical support [7].

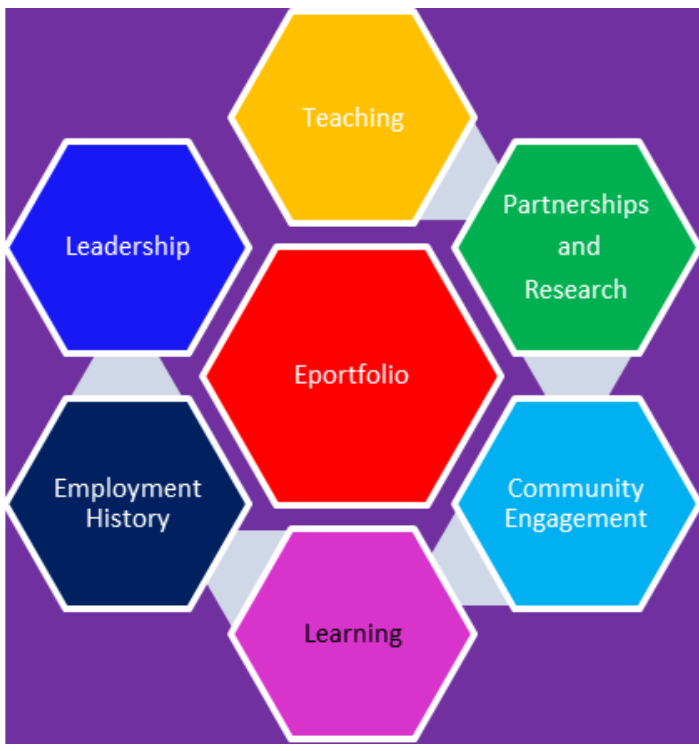

Figure 1. Academic Staff Eportfolio at ACU. Source:

Fisher \& Hill, 2014

In an earlier study conducted in 2013 by the Centre for Higher Education Research Melbourne Australia, findings indicated that curriculum, organisational structure and digital change was occurring at a faster rate than universities could accommodate, particularly in relation to supporting the adoption of new technologies like Eportfolio, used to store and profile evidence for learning, teaching and professional development activities [8].

Digital literacy that has emerged in its current form, according to recent research [9], comprises largely of students 'passively' consuming knowledge rather than more active practices. While this would not be the case in all universities or faculties at ACU, it is reasonable to assume that some academics who teach these students may justify their 'static' digital literacy as minimum standards they feel they need to attain to support their students' desire to only engage in 'surface learning' or bare minimum usage of digital technology engagement required by the university [6].

Opportunities for staff and students to engage with digital technology that integrates pedagogy at university, in practice may include: reviewing You Tube videos, lectures and communicating via online forums or submitting reflection type assessment through their Learning Management System (LMS). These activities may be a means of students achieving intended learning outcomes in a course, fulfilling graduate attributes and integrating learning with practice as well as technology [10].

Although at ACU the minimum digital requirement is for lecturers in charge (LICs) to upload an electronic copy of the unit outline as a pdf file into the specified unit site one week prior to students commencing a unit. In addition, students are expected to access the LMS daily for important messages and communications from the lecturer in charge and the University.

Higher Education recommendations presented in the Teaching Higher Education Standards Framework 2014, by the Federal Education Department, indicated that academic teaching staff needed to adapt their teaching to better serve student learning needs in the $21^{\text {st }}$ century. In Section 3 of this report it states that university teachers must provide 'progressive and coherent strategies' to encourage achievement of expected learning outcomes using available and emerging technologies [11]. Although the authors consider that staff may need to develop and model these practices by sharing learning and teaching ideas, working in groups and being recognised by the institution as leaders in their field more formally.

Kenny's research published in 2015 has shown that in practice, students are more likely to enhance their digital literacy by using an Eportfolio tool to overcome barriers to learning through sharing, collaborating and demonstrating connections between their units of study through academic, social and professional networking.

According to this recent analysis conducted in the United Kingdom that considered the impact of technological demands on $1^{\text {st }}$ year (Level 1) students, data revealed that using Eportfolios rather than paper based portfolios of evidence reduced student workload and stress relating to 'lost' paper evidence [12]. Academic and student accreditation or evidence of achievement can be demonstrated through accumulation of Eportfolio digital badges or stored in a virtual space rather than clogging networks with electronic documentation and artefacts [12]. This approach would potentially make data and evidence easier for academic staff to manage in the context of workload, and over time should result in academics feeling assessment of evidence is less time consuming.

\section{Australian Catholic University Structure (ACU)}

Under a federal Labor government (1983-1996) a national reform of higher education took place. One of the most significant changes to occur in Higher education was the amalgamation of 19 universities and 46 colleges of advanced education across Australia [13].

The Australian Catholic University was formed in 1991 following the amalgamation of four tertiary institutions in Eastern Australia. It covers 7 campuses in 4 states, New South Wales (NSW), Queensland (QLD), Victoria (VIC), South Australia (SA), and 1 territory, Australian Capital Territory 
(ACT) [2], [3]. The University emerged from the smaller teaching colleges established by clergy from a number of Catholic religious orders. The larger campuses situated in major cities in Sydney, with Melbourne and Brisbane managed by 3 Associate Vice Chancellors. Ballarat and Canberra campuses are led by a Campus Dean. Most campuses teach in the 4 faculties: Education \& Arts, Health Sciences, Law \& Business, and Theology \& Philosophy. Each State or Territory has their own legislation and requirements for professions in Law \& Business, Education, Nursing, Paramedicine and Social Work making the issue of uniformity with learning tools like Eportfolios problematic [2], [3].

\section{What is the Impact of Eportfolios in a Multiple Campus Environment?}

Digital literacy of academic staff varies greatly not just across campuses at ACU but across teacher age cohorts [3], [7]. It is not necessarily the older staff who struggle with digital literacy [3], [6], [7]. Academic staff in educational institutions make decisions to select, choose to engage with or resist adoption of technologies that would help them enhance learning, teaching and career development opportunities provided they feel confident adopting them [5], [7].

University executives have the perplexing task of selecting technology tools that serve multiple purposes in learning and teaching. At the same time they are trying to implement organisational technology decisions which are problematic due to the uncertain 'use by date' of new and emerging technology tools and managing rapid changes in the Higher Education environment that affect their institution [6], [7]. Uncertain government funding, competition with other institutions to attract students and challenges to remain relevant all contribute to the difficulty of balancing strategic vision with operational necessities such as finding solutions to support digital literacy [2], [3].

Some academic staff may feel uncertain about their level of skill, knowledge and the expectations of their students, when adopting technology that they might view as 'in fashion' this year and 'old news' the next [2], [7], [14]. While other academics view Information Communication Technology (ICT) skills as a preferred method of communicating effectively with students when engaging them in creative problem solving activities like involvement in 'the process' of using Eportfolios or reflective practice and profiling of evidence against professional accreditation for teachers [9].

A case study at the University of Minneapolis examined the role of reflection in Eportfolios in 2012. The data analysed in this study confirmed our observations at ACU that "Reflection was seldom the primary motivator for ePortfolio adoption, but its importance was quickly recognised and valued" [14] particularly for professional experience and related accreditation. The importance of reflective practice at ACU is becoming more widely accepted across faculties as an important part of professional development for academic teachers as well as students. A 'one size fits all' approach to academic digital support has not worked according to informal feedback from academic staff, especially those with diverse learning styles who prefer to be assisted by a person rather than proceed with online help.

There are still a number of challenges across campuses that continue to hinder the adoption, uptake and reporting on Eportfolio usage at ACU. Campus cultures, perception of the value (from Executive leadership) of Eportfolios at ACU and strategic vision may be unintentionally leading to the creation of power cliques centralized in one or two areas of the University [2], [3], [10], [15].

When the authors have tried to promote the use and adoption of EPortfolios at ACU, academics are confused about what is meant by the term [2], [3]. This is due to 'a fuzzy', too flexible concept of the definition of Eportfolio discussed in the context of university learning and teaching at ACU e.g. are we promoting the hosting system, Mahara or referring to pedagogy or scholarship of learning and teaching approaches integrated with a hosting system as an Eportfolio? [2], [3]. Academic teachers appear to be the autonomous agents of change in our University who influence the method and integration of Eportfolios in a positive or negative way depending on their knowledge, technical skills and motivation [15]. However, the complexity of culture, location and power cliques on some campuses makes it difficult to resolve from an Executive and academic staff perspective due in part to operational requirements that need to be met.

An interesting observation noted by the authors is that academics at ACU have reported informally that they are more interested in the type and level of support, especially for using the Eportfolio technology tool 'Mahara'. It is important for them to be able to access support when they need it most, often when students are submitting online assessment [2], [3], [16]. Academics' self-perception of the undefined workload required for technology enhanced and integrated learning varies greatly across the university sector [16]. The authors have observed that many academics at ACU would prefer to receive help from a person or attend a workshop face to face rather than work through online help facilities [20] as they consider that technology resides outside their allocated workload [2], [3], [15]. At ACU the authors have observed that many academics that only have access to online help frequently become frustrated and reluctant to use new technology for learning and teaching. The support resources are provided but what academics 
need most is support to facilitate diverse academic learning needs.

Complication with state based accreditation requirements (different in each state of Australia) for teaching, legal, business, nursing and paramedicine professions mean that it is impossible to negotiate a uniform 'one size fits all' Eportfolio pedagogy approach identified in the Europortfolio Implementation Policy, due to each area having a different context and needs [2], [3].

\section{Opportunities for the ACU Executive and Staff to integrate Eportfolio}

Despite the continuing difficulties with increasing uptake and adoption of Eportfolio at ACU, the authors would like to share some of the strategic decisions made by the Executive to streamline and improve services at our University. The Services Framework introduced in 2014, contained an ACU Service Catalogue [17]; Service Lead Responsibility Statement which guides Service leaders across the University; and an ACU Service Improvement Register, where project management guidelines are reviewed and revised. This framework was established together with a major restructure to improve service provision for staff and students including technological and digital communication. Human Resources (HR) were appointed as the Service Lead for professional development activities for professional and academic staff at ACU and the authors have observed that there is significant resistance (even if it is covert) from many areas in faculties due to HR's perceived or actual lack of understanding of academic work [7], [10], [6].

The impact on academic as well as professional staff has been significant in organization of work groups, work practices, engagement in teaching, research and integration of technology tools. There have been some staff who show signs of 'change fatigue' through their reluctance to embrace change due to unknown territory of 'how will this affect me?', which is understandable as people may be fearful of losing their jobs if they don't conform [7]. Others have welcomed the opportunity to reconsider the way they teach, engage students and integrate technology with pedagogy and communication with their colleagues [6], [7].

Despite this uncertainty about how jobs and service delivery will transform operations at ACU, the Executive have highlighted a unique opportunity to transform how evidence of achievement against key performance indicators could be recorded and assessed [13]. Integrating Eportfolio into the performance review, promotion or career development process to store and profile evidence of professional achievements and practice would be a forward step as the Executive progress their University reforms agenda via the Services
Framework, provided that staff have the opportunity to develop personal or intrinsic motivation through their work communities to pursue the teaching focused career track promotion or development opportunities [3], [11], [18], [20].

\section{Change Processes}

While centralizing and streamlining administration in an institution to reduce operating costs is nothing new in the $21^{\text {st }}$ century, academics are reporting that their workload is increasing due in part to taking on additional administration tasks [6] so they are unable or less likely to commit time to professional development associated with learning to use new technologies if it is not mandated, rewarded (indeed failed innovations can be punished in student evaluation survey reports on perceived digital literacy of academic staff) or deemed necessary to complete particular teaching tasks [16].

Additional administration is not the only change to the way contemporary academics are expected to work. Student-centered teaching means academics are engaging in online learning and teaching activities for a longer period of time, regulations and University rules are increasing and in many universities casualization of the academic workforce means that many staff are doing additional work outside their work contracts [7], [8]. Recent research by Tynan et al suggested that 'cost models' for teaching used by university executive teams to budget for teaching staff, while at the same time achieving savings relating to operating costs, are at odds with the actual time needed by experienced teaching academics, who may be sessional employees, to develop a unit online or via blended mode. Their estimate was based on an appraisal of Chapman Alliance statistics 2013 which indicated it takes 49 hours to create one finished hour of blended learning on average [16].

Although ACU is somewhat unique the authors acknowledge that the University has taken steps over the last 7 years to reduce casualization and this is evidenced by reclassifying some long term casual positions from casual to ongoing or permanent status for many people without the need for lengthy interview processes. This provides more stability for the students, faculties and schools and reduces the loss of university, discipline and corporate knowledge from ACU.

Upgrades to the Learning Management System (LMS) operating around the open-source Moodle Platform are frequent and occur at least once a year. Even though there are distinct benefits to staff when technology tools are made available to enhance their teaching opportunities, professional development needs to be offered to support eLearning changes. The impact of introducing regular changes on the University is a) ongoing professional development 
(PD), such as online help guides, self-service computer assisted learning, video tutorials, webinars or face to face workshops which can be time consuming to prepare and engage in with a continually diminishing half-life; b) some academics have reported informally that they become frustrated and reluctant to engage with technology if 'it changes from one semester to the next' and c) 'What is in it for me?' [5], [7] or will it stop me doing what I need to do?

The changed learning and teaching practices need to be 'sold' to the staff not by the Executive but by their colleagues (who may be enthusiastic adopters working in communities on campus) who should be able to demonstrate a range of benefits of integrating technology, while at the same time recognising diverse learning styles, with pedagogy to achieve University objectives in the learning and teaching milieu [2], [3], [20].

\section{Transformative learning - Ways to Move Forward}

The main transformative learning approach used in developing student Eportfolios at ACU in the Education and Health Sciences faculties is reflective practice [2], [3]. At ACU Education and Health Sciences academics and students continue to be active users for accreditation of teachers, nurses and paramedics [2], [3].

A simple reflective practice can be used to determine:

a) What is working well? What learning strategies employed produced good results?

b) What needs changing? If my learning outcomes were poor, what other strategies could I use to improve my practice?

c) What are we learning? How can I 'transfer' my prior learning into this context?

d) Where do we go from here? How do I reassess and adjust my goals [19]? This approach could help reluctant staff take the first steps to profile their own experience for a particular purpose such as promotion or fulfilling probation requirements.

Staff and students less familiar with reflective practice should be able to ease into new strategies for collecting, profiling and managing evidence of their own learning [19]. A simple reflective approach may encourage academics to act as change agents, increasing the uptake and adoption of Eportfolio by academic staff as well as students at ACU particularly as they were active in a Community of Practice where experiences could be shared (in a trusted, supportive, non-judgmental environment concept of dialogue $\mathrm{v}$ discussion suggested by the scientist Bohm and used as an intrinsic motivator to enable the learner to exercise their capacity to seek out and overcome challenges with support from their campus communities [13].

\section{Review Policy for Future Practice}

The Eportfolio Policy at ACU needs to be reviewed to reflect the short, medium and long term needs of students to enable them to become:

a) Reflective practitioners critically analyzing, refining and transferring learning from experience developed through their professional behavior (including teaching and learning), work practices and academic studies [8];

b) Highly sought after graduates due to actual and perceived adaptability to future, possible work environments.

c) Self-regulation, collaborative learners who may consider: what is working/not working? What do I need to change? How can I learn or develop my living story through strengths and weaknesses [20].

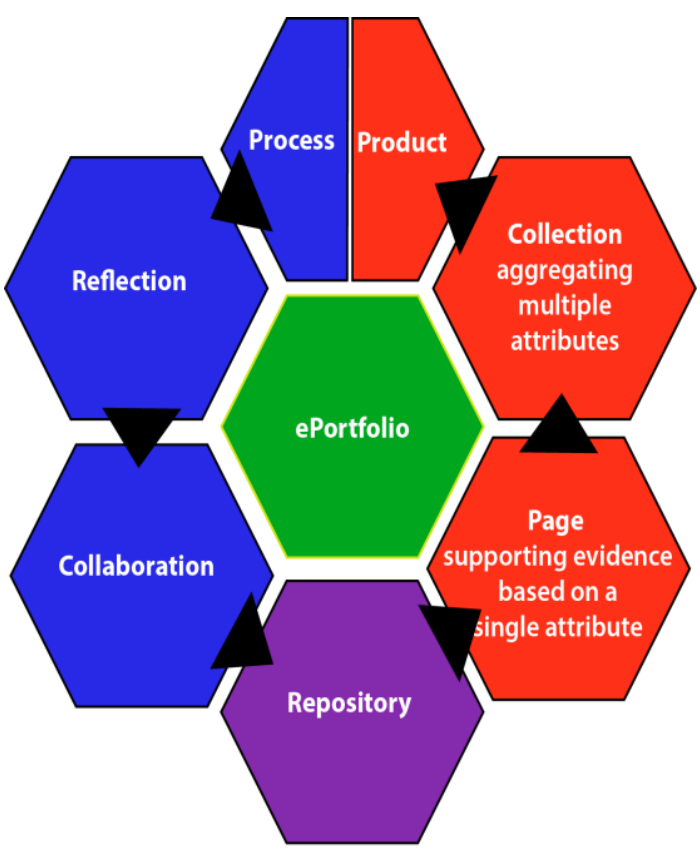

Figure 2. Eportfolio Model 2 - Process to Product, Source: Fisher \& Hill, 2015

Clear direction from the University Administration informs policy development and is needed to inform how staff should engage in the process of integrating pedagogy with technology. A simple process is needed for staff to help students create, maintain and profile their evidence and build their evolving digital story which is essential in the professions. If staff are modelling best practice in the Eportfolio process with students and ensuring that their pedagogy continues to be integrated with technology tools for learning and teaching, students are more likely to be encouraged to view integration of technology and pedagogy as a 'living' process where milestones profile learning products.

More importantly the 'products' continue to evolve and effect transformative learning rather than 
becoming a static repository of materials or artefacts. Feedback from international colleagues at the LICE 2015 conference from Finland who are integrating pedagogy with technology in this way, with a clear policy and guidelines have reported more success encouraging student uptake and continuous engagement in their learning.

Academics should be able to use this policy to develop relevant, current and future practices in a collaborative environment integrating pedagogy with technology. Eportfolios need to be embedded into degree courses and established as framework or scaffold across courses by units of study to stimulate curriculum renewal [19].

\section{Conclusions}

Eportfolio implementation is no easy task. However, it is worthwhile due to the many benefits to learning, teaching and profiling one's career through the processes to obtain the product. As the authors tried to progress Eportfolio across the University, provide pedagogical and eLearning support as well as encourage usage they realised that pressures on the Executive to select digital solutions for accreditation, performance review and career development for ACU staff were more complex than first envisaged due to: challenges with digital literacy of staff and students; disruptive change in the Higher Education milieu and organisational change and cost. The authors recognized these challenges hindering adoption and continue to encourage a commitment by the Executive to:

Designate a member of their team to drive the project;

Lead a Community of Practice to be developed on each campus to promote peer collaboration, address workload issues and encourage adoption, share pedagogical practices aligned learning outcomes; [12], [7].

In addition, we welcomed suggestions from the Global community particularly in the area of multiple campus technology implementation, adoption and ideas to increase intrinsic motivation of staff to utilize and challenge themselves with Eportfolio activities and incorporate personal learning into their teaching activities.

Suggestions from academics in Finland supported the need for clear policy and guidelines as well as digital literacy support for academics so they could model best practice and engage Eportfolio tools with relevant pedagogy to improve learning opportunities. Strategies employed by the Executive in our University and other academic institutions to support and encourage an increase in digital literacy across campuses in a milieu of disruptive change are an important factor in successful Eportfolio implementation at ACU. Technology tools that are not integrated into curriculum and across academic courses may be assigned to the 'too hard basket' by the Executive and teaching staff if digital literacy is not improved and supported in a cost effective, timely way preferably 'on demand'.

The consequences for our University would be high given the competitive nature of higher education in Australia and overseas in a multiple campus environment. While preparing this article the Faculty of Education and Arts (FEA) at ACU had commenced embedding Eportfolio into assessment. Eportfolios will be integrated into the professional experience component of units to help students collect and profile evidence of professional teaching practice as evidence for accreditation and achieving required teaching standards. This requirement will be embedded in all units and undergraduate courses for implementation in 2016. Meanwhile the authors continue to promote uptake and adoption of Eportfolios at ACU, in Australia and overseas by: documenting their experience using a Scholarship of Learning and teaching approach; reviewing recent research and accommodating feedback through connections with colleagues in Australia and overseas.

\section{References}

[1] Johnson, Ruth. S, Mims-Cox, J. Sabrina \& DoyleNichols, Developing Portfolios in Education: A Guide to Reflection, Inquiry, and Assessment, Sage Publishing, USA, 2010.

[2] Marie B. Fisher \& Andrew J. Hill, "Eportfolio Adoption and Implementation in a Multiple Campus University Environment - a Reflection on Opportunities and Challenges in Learning and Teaching at the Australian Catholic University" 2014, LICE -2014, London International Conference on Education Proceedings, p.345, Infonomics Society, 2014, London, United Kingdom.

[3] Marie B. Fisher, \& Andrew J Hill "Eportfolio Adoption and Implementation in a Multiple Campus University Environment", Literacy Information and Computer Education Journal (LICEJ), Volume 6, Issue 1, London, UK, March 2015.

[4] U. Coffey, and K. Ashford-Rowe, "The Changing Landscape of Eportfolios: A Case Study in one Australian University", Australasian Journal of Educational Technology, Australia, 2014, 30(3).

[5] Laurie Posey, Margaret M. Plack, Robert Snyder, Robert, Patricia Low Dinneen, Melissa Feuer and Andrew Wiss, "Developing a Pathway for an Institution Wide Eportfolio Program", International Journal of Eportfolio, Volume 5: 1, 2015, 75-92.

[6] Simon McIntyre, "Reducing the digital literacy divide through disruptive innovation", HERDSA Review of Higher Education, Vol. 1, The University of New South Wales, Australia, 2014. Located at: www.herdsa.org.au 
[7] NTEU State of the Uni Survey - Overview Report No. 1\& 2' National Tertiary Education Union, Australia, 22 July 2015, Australia.

[8] Simon Marginson, "Tertiary Education Policy in Australia" Centre for the Study of Higher Education, University of Melbourne, Australia, 2013.

[9] M. Henderson, N. Selwyn, G. Finger, \& R. Aston, "Students' everyday engagement with digital technology in university: exploring patterns of use and 'usefulness", Journal of Higher Education Policy and Management, Routledge, Australia, 2015 37:3, pp. 308-319.

[10] A.Kehoe, \& M. Goudzwaard, ePortfolios, Badges, and the Whole Digital Self: How Evidence-Based Learning Pedagogies and Technologies Can Support Integrative Learning and Identity Development. Theory into Practice, 2015, 54.4, pp. 343-351. http://dx.doi.org/10.1080/00405841.2015.1077628

[11]Department of Education, Australia, Higher Education Standards Framework 2014 located at: https://www.education.gov.au/final-proposed-highereducation-standards-framework.

[12]Kenny, Anita, Motivated for Learning? The introduction of e-portfolios to level 1 students in a Further Education college. The Journal of Technology Enhanced Learning, Innovation and Change, 2015, Volume 1, Issue 1 .

[13] Bessant, J. "Dawkins' Higher Education Reforms and How Metaphors Work in Policy Making". Journal of Higher Education Policy and Management, 24:1, 87-99, Australia, 2002.

[14] Cynthia M. Landis, Susan B. Scott, \& Susan Kahn, "Examining the Role of Reflection in ePortfolios: A Case Study". International Journal of ePortfolio, USA, 2015, V.5, No. 2, pp.107-121.

[15] Punya, Mishra, Matthew J. Koehler, "Technological Pedagogical Content Knowledge (TPCK): Confronting the Wicked Problems of Teaching with Technology Proceedings", Society for Information Technology \& Teacher Education International Conference, Mar 26, 2007 in San Antonio, Texas, USA, Association for the Advancement of Computing in Education (AACE), Chesapeake, VA, Michigan State University, USA, 2007, pp. 2214-2226.

[16] B. Tynan, Y. Ryan, \& A. Lamont-Mills, "Examining workload models in online and blended teaching", British Journal of Educational Technology, UK, 2015, V.46 No.1, pp.5-15.

[17] ACU Service Matters Framework 2014. http://www.acu.edu.au/staff/our_university/newsroom/new _archive/service_matters_framework

[18] R.M. Ryan, \& E.L. Deci, E. L. Self-determination theory and the facilitation of intrinsic motivation, social development, and well-being. The American Psychologist, USA, 55(1), 2000, pp. 68-78. http://doi.org/ 10.1037/0003-066X.55.1.68
[19]Tony Gahye, Teaching and Learning through Reflective Practice: A Practical Guide for Positive Action, Routledge, London, 2011.

[20] Robyn Henderson, Karen Noble, Professional learning, induction and critical reflection: Building Workforce Capacity in Education, 2015, Palgrave pivot USQ. 